\title{
AMCoR
}

Asahikawa Medical College Repository http://amcor.asahikawa-med.ac.jp/

Journal of Bone and Joint Surgery (2004 Jul.) 86(A7):1439-1445.

Chiari pelvic osteotomy for advanced osteoarthritis in patients with hip dysplasia.

Ito, Hiroshi ; Matsuno, Takeo ; Minami, Akio 
The Journal of Bone E Joint Surgery
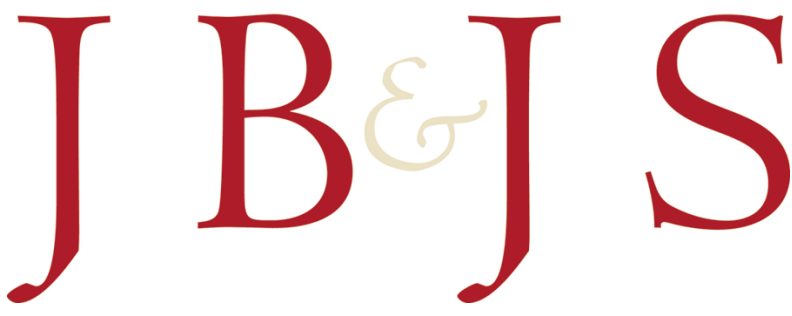

This is an enhanced PDF from The Journal of Bone and Joint Surgery

The PDF of the article you requested follows this cover page.

\section{Chiari Pelvic Osteotomy for Advanced Osteoarthritis in Patients with Hip Dysplasia}

Hiroshi Ito, Takeo Matsuno and Akio Minami

J Bone Joint Surg Am. 2004;86:1439-1445.

Subject Collections

Reprints and Permissions

Publisher Information
This information is current as of December 6, 2007

Articles on similar topics can be found in the following collections

\author{
Adult Disease (1282 articles) \\ Adult Hip (455 articles) \\ Hip (521 articles) \\ Osteoarthrosis (151 articles) \\ Congenital Anomalies (87 articles) \\ Developmental Dysplasia - Hip (56 articles) \\ Surgical Procedures (693 articles)
}

Click here to order reprints or request permission to use material from this article, or locate the article citation on jbjs.org and click on the [Reprints and Permissions] link.

The Journal of Bone and Joint Surgery

20 Pickering Street, Needham, MA 02492-3157

www.jbjs.org 


\title{
Chiari Pelvic Osteotomy FOR ADVANCED OSTEOARTHRITIS IN Patients With Hip Dysplasia
}

\author{
By Hiroshi Ito, MD, TAKeo Matsuno, MD, And AKio Minami, MD \\ Investigation performed at Asahikawa Medical College, Asahikawa, Japan
}

\begin{abstract}
Background: It is not clear whether a Chiari pelvic osteotomy performed for the treatment of advanced osteoarthritis can delay the need for total hip arthroplasty. We present the mid-term results of the Chiari pelvic osteotomy performed for the treatment of Tönnis grade-3 osteoarthritis (large cysts, severe narrowing of the joint space, or severe deformity or necrosis of the head with extensive osteophyte formation), with a particular focus on whether this procedure can delay the need for total hip arthroplasty.
\end{abstract}

Methods: We followed thirty-two hips in thirty-one patients with Tönnis grade-3 osteoarthritis who had refused total hip arthroplasty and had been treated with a Chiari pelvic osteotomy. The mean age at the time of surgery was 35.2 years. The mean duration of follow-up was 11.2 years, at which time clinical evaluation with the Harris hip score and radiographic evaluation were performed.

Results: The average Harris hip score improved from 52 points preoperatively to 77 points at the time of follow-up; the average pain score improved from 20 to 31 points. Three hips with a hip score of $<70$ points required total hip arthroplasty. With a hip score of $<70$ points as the end point, the cumulative rate of survival at ten years was $72 \%$. The clinical outcome was significantly influenced by the preoperative center-edge angle $(p=0.004)$, the preoperative acetabular head index $(p=0.039)$, achievement of the appropriate osteotomy level $(p=0.011)$, and superior migration $(p=0.009)$ and lateral migration $(p=0.026)$ of the femoral head.

Conclusions: Although the clinical results were inferior to those of total hip arthroplasty, Chiari pelvic osteotomy may be an option for young patients with advanced osteoarthritis who prefer a joint-conserving procedure to total hip arthroplasty and accept a clinical outcome that is predicted to be less optimal than that of total hip arthroplasty. Moderate dysplasia and moderate subluxation without complete obliteration of the joint space and a preoperative center-edge angle of at least $-10^{\circ}$ are desirable selection criteria.

Level of Evidence: Therapeutic study, Level IV (case series [no, or historical, control group]). See Instructions to Authors for a complete description of levels of evidence.

$\mathrm{T}$ he management of severe osteoarthritis due to hip dysplasia in younger and more physically active patients is controversial. If possible, total hip arthroplasty is best avoided in young patients because of its limited durability ${ }^{1-3}$, even with recent improvements ${ }^{4}$. Joint-preserving procedures include femoral osteotomy, arthrodesis, and acetabular osteotomy. The goals of surgical intervention are to relieve pain and delay the progression of the arthritis. Ideally, after failure of a joint-preserving procedure, it should be possible to perform a total hip arthroplasty with a low complication rate and acceptable durability.

Chiari described a medial displacement pelvic osteotomy for the treatment of subluxation of the hip in 1955 and reported good short-term results after five years ${ }^{5}$. This procedure provides osseous coverage of the femoral head and re- duces the load across the hip by displacing the hip joint medially. In series ranging in size from thirty-two to 236 osteotomies ${ }^{6-12}$, good mid-term to long-term clinical results have been reported in $51 \%$ to $92 \%$ of hips with early stage osteoarthritis. Whether this procedure, when performed for the treatment of advanced osteoarthritis, can delay the need for total hip arthroplasty is not clear. To address this issue, we studied the mid-term results of Chiari pelvic osteotomy performed for the treatment of advanced osteoarthritis in a series of patients with hip dysplasia.

\section{Materials and Methods}

B etween January 1976 and April 1998, thirty-four Chiari $\mathrm{B}_{\text {pelvic osteotomies were performed in thirty-three consec- }}$ utive patients for the treatment of advanced osteoarthritis sec- 
The Journal of Bone \& JoInt Surgery - JBJS.Org VOLUMe 86-A · Number 7 · JuLY 2004

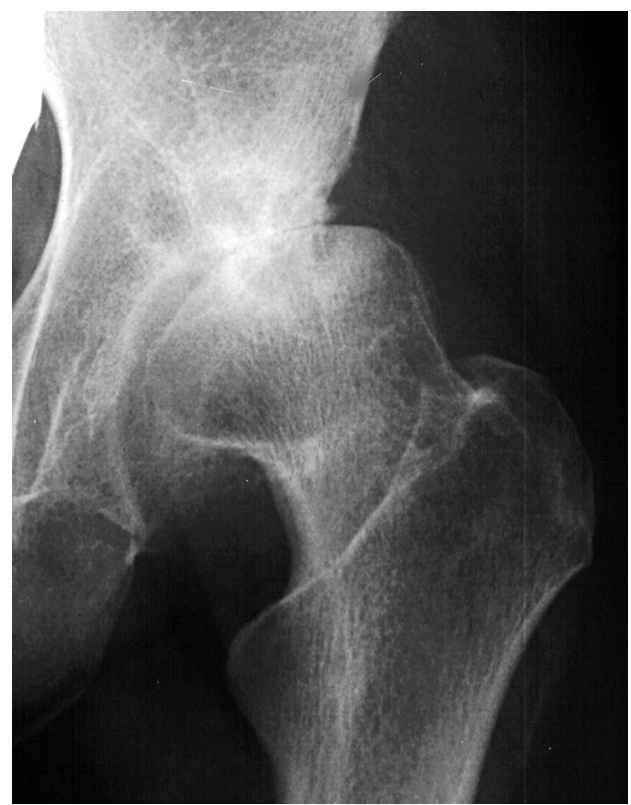

Fig. 1-A

Figs. 1-A, 1-B, and 1-C A thirty-three-year-old woman with subluxation of a deformed femoral head. She had undergone open reduction of the dislocated hip at five months of age. Fig. 1-A The radiograph made before the Chiari osteotomy demonstrates cysts in the femoral head and the acetabulum as well as severe deformity of the head with poor congruity with the acetabulum. Although the superior weight-bearing joint space is obliterated, some residual medial joint space is present.

ondary to hip dysplasia. Preoperative radiographs of all thirtyfour hips showed grade- 3 osteoarthritis according to the criteria proposed by Tönnis ${ }^{13}$ - i.e., large cysts in the femoral head or acetabulum, severe narrowing of the joint space, or severe deformity or necrosis of the head with extensive osteophyte formation. Preoperative radiographs of these hips did not show, however, complete obliteration of the joint space. The patients had refused total hip arthroplasty after being told that a future revision arthroplasty was likely. They preferred to undergo a Chiari pelvic osteotomy as a joint-preserving option with the knowledge that postoperative functional improvement might be limited. Two hips (two patients) were lost to follow-up. The remaining thirty-two hips in thirty-one patients were available for clinical and radiographic review. The average patient age at the time of the index surgery was 35.2 years (range, sixteen to fifty years), and the average patient weight was $56.3 \mathrm{~kg}$ (range, 45 to $77 \mathrm{~kg}$ ). Four patients were male, and twenty-seven were female. Seventeen left hips and fifteen right hips were treated. The mean duration of followup was 11.2 years (range, 5.0 to 24.5 years). Each patient had a minimum of $45^{\circ}$ of flexion and $10^{\circ}$ of abduction before the surgery.

Three different approaches were used for this procedure. An anterior iliofemoral approach without a trochanteric osteotomy was used, with the incision described by Chiari ${ }^{5}$, in the first three hips that were treated. The pelvic osteotomy line was cut straight with a Gigli saw. In the next thirteen hips, treated from
Chiari Pelvic Osteotomy for Advanced Osteonthritis in Patients With Hip Dysplasia

1978 to 1990 , a posterolateral approach with a trochanteric osteotomy was used to achieve the pelvic osteotomy at the most appropriate level and to advance the greater trochanter distally (Figs. 1-A through 2-C). A dome-shaped pelvic osteotomy was cut with use of a reciprocating saw. In the remaining sixteen hips, treated from 1990 to 1998, an Ollier lateral u approach with a trochanteric osteotomy was used ${ }^{14}$. Intraoperative radiography or fluoroscopy was used routinely. Fixation was achieved

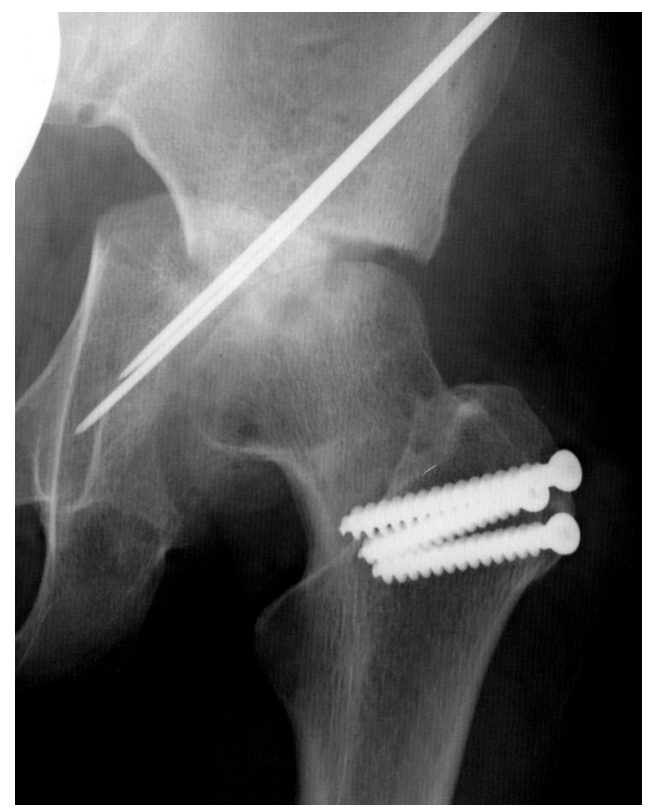

Fig. 1-B

A Chiari pelvic osteotomy was performed through a posterolateral approach. Two weeks after the surgery, there was good coverage of the femoral head and the osteotomy level was considered to be appropriate.

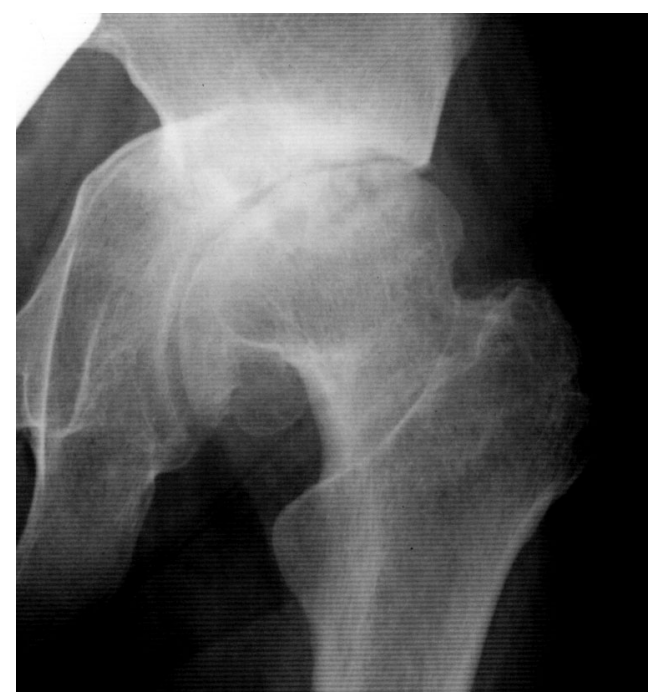

Fig. 1-C

Ten years after the surgery, there was good congruity between the femoral head and the acetabulum and the joint space was preserved. The patient reported that she had no hip pain (a pain score of 40 of 44 possible points), and she did not have a Trendelenburg gait. 
The Journal of BOnE \& JOINT SuRgERY • JBJS.ORG VOLUME 86-A · NUMBER 7 · JULY 2004

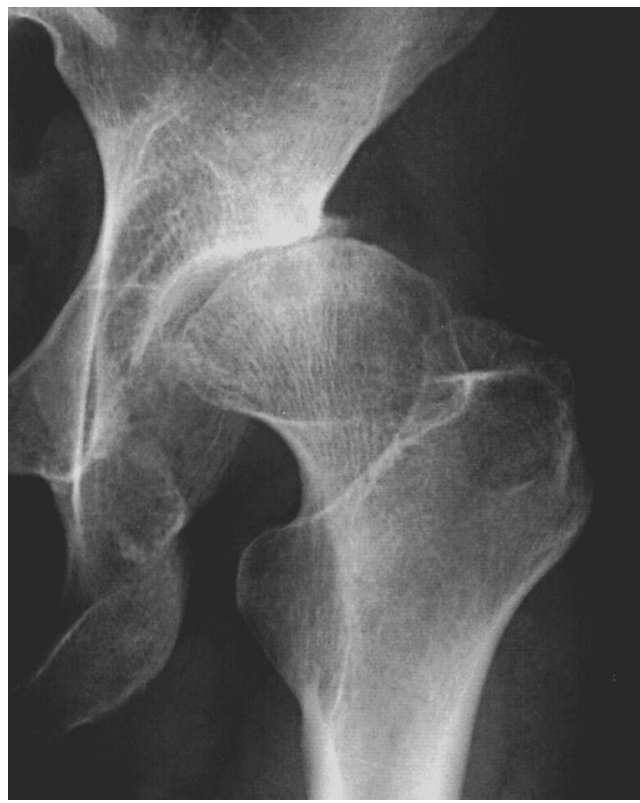

Fig. 2-A

Figs. 2-A, 2-B, and 2-C Radiographs of a thirty-four-year-old woman with acetabular dysplasia and a deformed femoral head. The congenitally dislocated hip had been reduced by overhead traction and manual manipulation when the patient was twenty months of age. The patient weighed $70 \mathrm{~kg}$ at the time of the osteotomy. Fig. 2-A The preoperative radiograph shows cysts and osteophytes in the femoral head and the acetabulum, severe narrowing of the joint space, and severe deformity of the head with poor congruity with the acetabulum. A Chiari pelvic osteotomy and distal advancement of the greater trochanter was performed with use of an Ollier lateral u approach.

with use of bone-pegs in seven hips and Kirschner wires or metal screws in twenty-five hips. A femoral valgus osteotomy was also performed in three hips in which the femoral head was distorted and in which preoperative radiographs had shown good congruity between the femoral head and the acetabulum with the hip in an adducted position.

Neither postoperative traction nor cast immobilization was used. After two weeks of bed rest, the patients were allowed to use a wheelchair, and walking without weight-bearing was allowed as tolerated. Partial weight-bearing was begun six weeks after the surgery when a pelvic osteotomy alone had been performed and eight weeks after the surgery when combined pelvic and femoral osteotomies had been performed. Full weightbearing was started twelve weeks postoperatively.

Clinical evaluation was performed according to the Harris hip-scoring system ${ }^{15}$. Evaluation of preoperative and follow-up anteroposterior and lateral radiographs included measurement of the center-edge angle of Wiberg ${ }^{16}$, the acetabular head index, and the acetabular angle of Sharp ${ }^{17}$. The acetabular head index is the same as the acetabulum-femoral head quotient described by Heyman and Herndon ${ }^{18}$. Lateral and superior migration of the femoral head was measured by comparing initial postoperative radiographs with those made
Chiari Pelvic Osteotomy for Advanced Osteoarthritis in Patients With Hip Dysplasia

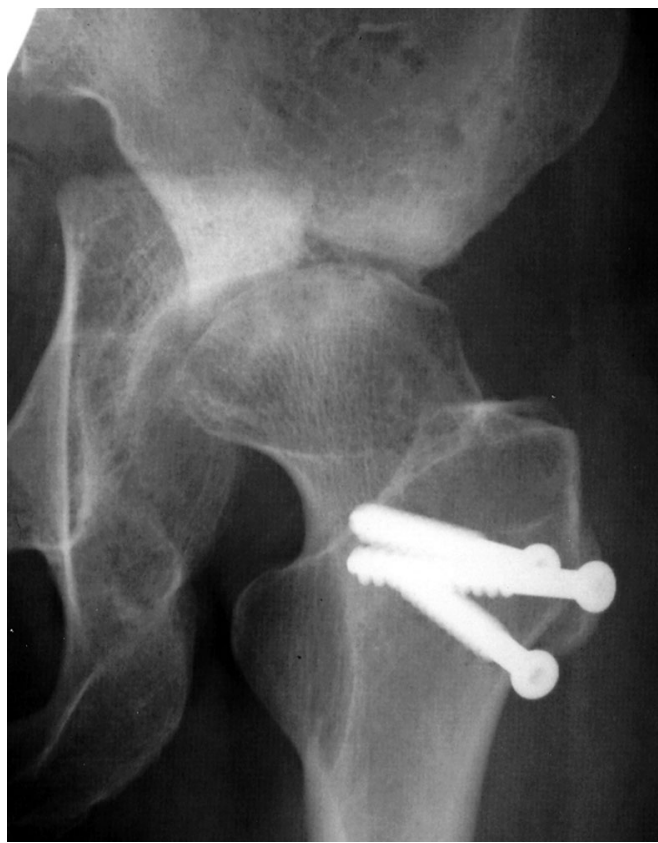

Fig. 2-B

Six weeks after the surgery, there was good coverage of the femoral head and an appropriate osteotomy level.

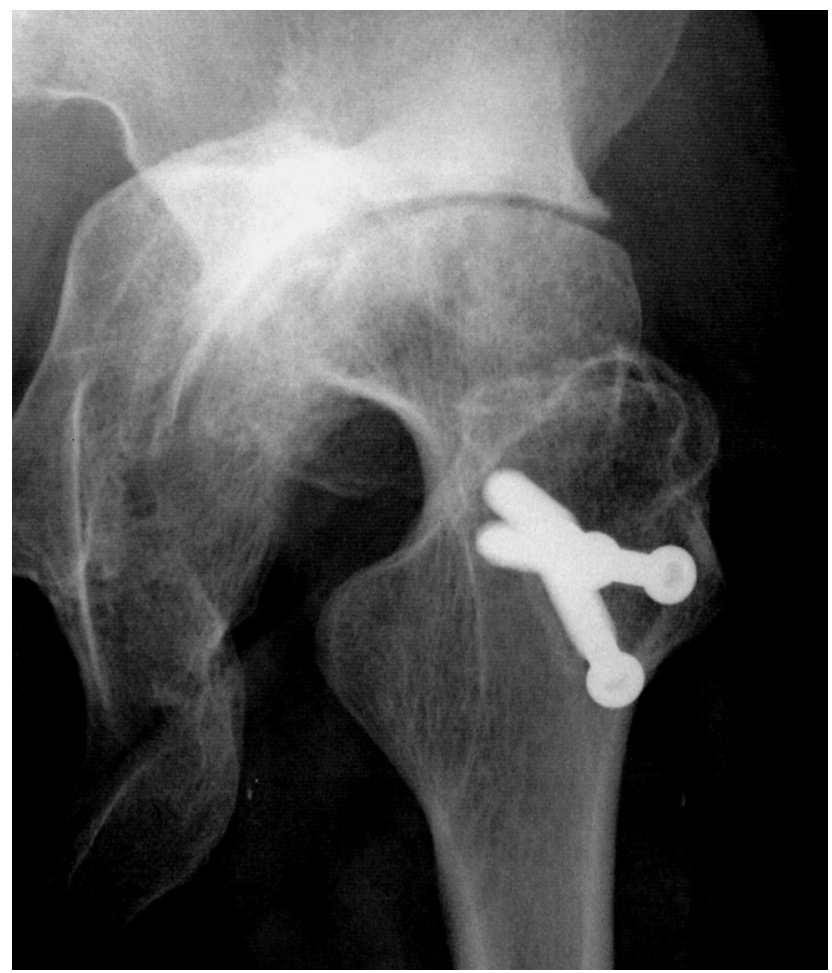

Fig. 2-C

Eleven years after surgery, the deformity of the femoral head had progressed, but there was improvement in the congruity between the femoral head and the acetabulum without progressive narrowing of the joint space. The patient reported that she had almost no hip pain (a pain score of 40 points). 
The Journal of Bone \& JOINT SURGERY • JBJS.ORG VOLUME 86-A · NUMBER 7 · JULY 2004
Chiari Pelvic Osteotomy for Advanced Osteoarthritis in Patients With Hip Dysplasia

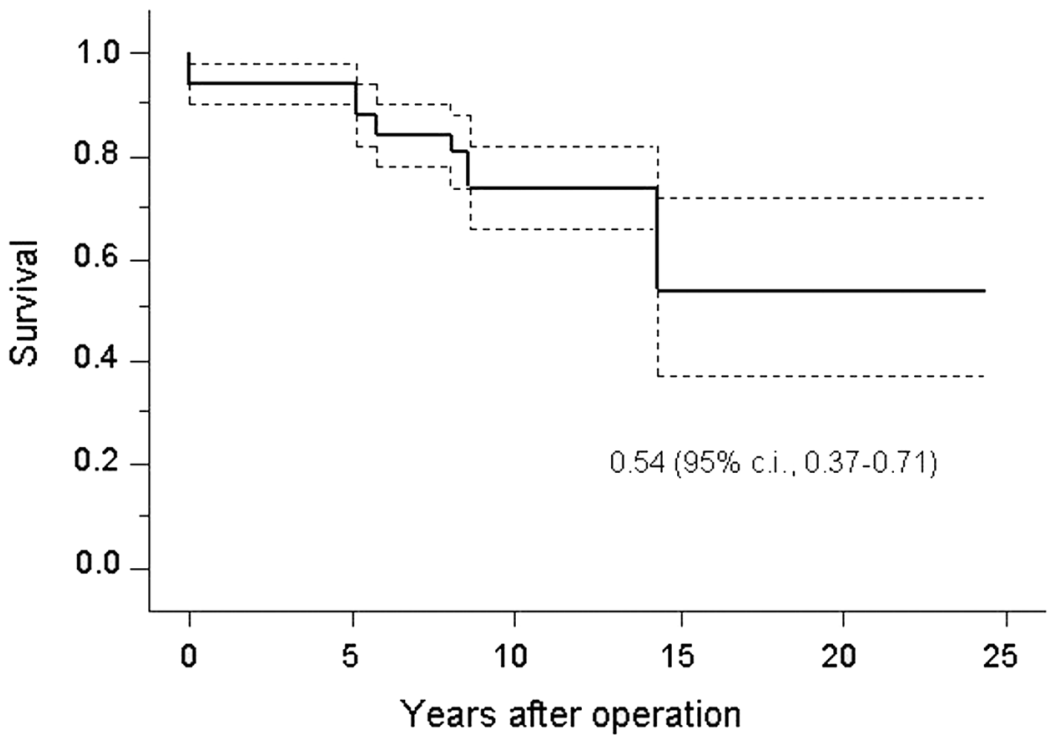

Fig. 3

The survival curve for hips managed with Chiari pelvic osteotomy, with a hip score of $<70$ points as the end point.

at the time of follow-up'. The level of the osteotomy was considered to be appropriate when it had been placed between 0 and $10 \mathrm{~mm}$ from the superior osseous margin of the acetabulum'. Sphericity of the femoral head was also measured preoperatively, with use of Mose circle templates. The femoral head was classified as regular when the outline was in the zone defined by concentric circles spaced $2 \mathrm{~mm}$ apart, irregular when it was in the zone defined by concentric circles spaced $6 \mathrm{~mm}$ apart, and very irregular when it was in the zone defined by concentric circles spaced $\geq 7 \mathrm{~mm}$ apart.

Statistical analysis was performed with use of StatView statistical software (SAS Institute, Cary, North Carolina). Univariate analysis included the chi-square test, the Wilcoxon signed-rank test, and the Mann-Whitney U test. Multivariate analysis with the Scheffé post hoc test was performed when a significant difference was demonstrated by one-factor analysis of variance. A probability value of $<0.05$ was considered significant. Kaplan-Meier survivorship curves were calculated to examine the rate of failure with $95 \%$ confidence intervals. The end point was defined as a hip score of $<70$ points at the latest follow-up examination or the performance of a total hip arthroplasty.

\section{Results}

The mean preoperative Harris hip score (and standard de1 viation) was $52 \pm 10$ points, which improved to $77 \pm 14$ points at the most recent follow-up examination $(\mathrm{p}<0.0001)$. The mean preoperative pain score was $20 \pm 6$ points (of 44 possible points), which improved to $31 \pm 9$ points at the time of follow-up $(\mathrm{p}<0.0001)$. The mean preoperative functional score, including points substracted for deformity and points for range of motion, improved from $32 \pm 6$ points (of 56 possible points) to $45 \pm 6$ points at the time of follow-up ( $p<$ 0.0001). A limp because of a mild limb-length discrepancy and a limited range of motion were the main reasons for lower functional scores at the time of follow-up. The average preop- erative limb-length discrepancy was $-0.8 \mathrm{~cm}$ (range, -3 to +2 $\mathrm{cm}$ ), and the average discrepancy at the time of follow-up was $-1.7 \mathrm{~cm}$ (range, -4 to $+1 \mathrm{~cm}$ ). Nineteen hips (59\%) were associated with a slight or moderate limp at the time of follow-up, and in that group the limb on the involved side was an average of $1.5 \mathrm{~cm}$ shorter than the contralateral limb. These hips were either not or only mildly painful. Six hips had a high-riding greater trochanter preoperatively, and the greater trochanter was advanced distally by 1 to $2.5 \mathrm{~cm}$ at the time of the surgery.

At the latest follow-up examination, the hip score was $\geq 70$ points for twenty-three hips $(72 \%)$ and $<70$ points for nine. Of the nine hips, three treated with Chiari osteotomy alone required total hip arthroplasty, 14.0, 8.0, and 5.1 years after the osteotomy. The hip scores of these three patients just prior to the total hip arthroplasty were 44,46 , and 56 points.

The hip scores of the three hips treated with simultaneous femoral valgus osteotomy and Chiari osteotomy were 52, 52, and 40 points preoperatively and 74, 78, and 68 points at the time of follow-up, respectively. Those scores were not significantly different from the scores for the twenty-nine hips treated with Chiari osteotomy alone. With a hip score of $<70$ points as the end point, the cumulative rates of survival were $72 \%$ (95\% confidence interval, $0.64 \%$ to $0.81 \%$ ) at 10.0 years and $54 \%$ (95\% confidence interval, $0.37 \%$ to $0.71 \%$ ) at 20.0 years (Fig. 3 ).

The radiographic assessment showed progression of the osteoarthritis, as reflected by more extensive osteophytes or larger cysts, in twenty hips $(63 \%)$. The size of the cysts in the acetabulum or the femoral head diminished in eight hips $(25 \%)$. The average preoperative center-edge angle was $-6^{\circ}$, which improved to an average of $30^{\circ}$ postoperatively. The average acetabular head index improved from 52\% preoperatively to $89 \%$ postoperatively, and the average Sharp angle improved from $50^{\circ}$ to $40^{\circ}$.

The relationship between the clinical results and various factors is summarized in Table I. Multivariate analysis with the 
The JOURnAl of BOnE \& JOINT SURGERY • JBJS.ORG VOlume 86-A · Number 7 • July 2004
Chiari Pelvic Osteotomy for Advanced Osteoarthritis in Patients With Hip Dysplasia

TABLE I Relationship Between the Clinical Results and Various Factors

\begin{tabular}{|c|c|c|c|}
\hline Factor & $\begin{array}{l}\text { Hip Score } \geq 70 \text { points* } \\
\qquad(\mathrm{N}=23)\end{array}$ & $\begin{array}{l}\text { Hip Score < }>70 \text { points* } \\
\qquad(\mathrm{N}=9)\end{array}$ & $P$ Value \\
\hline Duration of follow-up (yr) & $11.1 \pm 4.3$ & $11.3 \pm 5.0$ & $0.916 \dagger$ \\
\hline Body weight (kg) & $56 \pm 9$ & $58 \pm 6$ & $0.275 \dagger$ \\
\hline \multicolumn{4}{|l|}{ Center-edge angle ${ }^{16}$ (deg) } \\
\hline Preoperative & $-4 \pm 5$ & $-10 \pm 5$ & $0.008 \dagger$ \\
\hline Postoperative & $31 \pm 6$ & $30 \pm 7$ & $0.784 \dagger$ \\
\hline \multicolumn{4}{|l|}{ Acetabular head index ${ }^{18}(\%)$} \\
\hline Preoperative & $53 \pm 5$ & $48 \pm 5$ & $0.034 \dagger$ \\
\hline Postoperative & $89 \pm 8$ & $89 \pm 6$ & $0.689 \dagger$ \\
\hline \multicolumn{4}{|l|}{ Sharp angle ${ }^{17}$ (deg) } \\
\hline Preoperative & $50 \pm 3$ & $52 \pm 5$ & $0.262 \dagger$ \\
\hline Postoperative & $40 \pm 3$ & $41 \pm 3$ & $0.485 \dagger$ \\
\hline \multicolumn{4}{|l|}{ Sphericity (no. of hips) } \\
\hline Regular & 5 & 1 & \\
\hline Irregular & 14 & 4 & $0.273 申$ \\
\hline Very irregular & 4 & 4 & \\
\hline \multicolumn{4}{|l|}{ Migration $(\mathrm{mm})$} \\
\hline Superior & $4.6 \pm 3.4$ & $8.2 \pm 3.5$ & $0.012 \dagger$ \\
\hline Lateral & $3.8 \pm 2.1$ & $5.1 \pm 1.9$ & $0.009 \dagger$ \\
\hline \multicolumn{4}{|l|}{ Osteotomy line (no. of hips) } \\
\hline Low & 0 & 2 & \\
\hline Appropriate & 20 & 4 & 0.018 † \\
\hline High & 3 & 3 & \\
\hline
\end{tabular}

Scheffé post hoc test showed significant associations between the Harris hip score and the preoperative center-edge angle $(\mathrm{p}=0.004)$, the preoperative acetabular head index $(\mathrm{p}=$ $0.039)$, the appropriate osteotomy level $(\mathrm{p}=0.011)$, superior migration of the femoral head $(\mathrm{p}=0.009)$, and lateral migration of the femoral head $(\mathrm{p}=0.026)$. Twenty-two $(85 \%)$ of twenty-six hips with a preoperative center-edge angle of $-10^{\circ}$ or more had a hip score of 70 points or more. This percentage was significantly greater than the percentage of hips $(17 \%$, one of six) with a preoperative center-edge angle of less than $-10^{\circ}$ that had a hip score of 70 points or more $(\mathrm{p}=0.0008)$.

No hip had nonunion of an osteotomy site, including the greater trochanter. There were no other major complications such as deep infection or pulmonary embolism.

\section{Discussion}

$\mathbf{R}$ eynolds $^{11}$ found the clinical results of Chiari pelvic osteotR omy to be unsatisfactory for the treatment of advanced osteoarthritis and concluded that it is not indicated for patients with severe degeneration. Matsuno et al. ${ }^{9}$ stated that a Chiari pelvic osteotomy should not be done in patients with severe arthritic changes; however, the results in those patients were deemed to be disappointing in comparison with those of patients with no or early-stage osteoarthritis. We propose that if a reconstructive procedure for advanced osteoarthritis maintains acceptable joint function and delays the need for total hip arthroplasty, it can be considered to be an effective procedure.

Ferguson et al. ${ }^{19}$ reported technical problems during the surgery in 23\% of 305 hips that underwent total hip arthroplasty after failure of an intertrochanteric osteotomy; the perioperative complication rate was $11.8 \%$. Few reports have described complications and technical problems associated with total hip arthroplasty after failed Chiari osteotomy ${ }^{8,10,20,21}$. Lack et al. ${ }^{8}$ reported that twenty of 100 hips underwent total hip arthroplasty at an average of 11.5 years after a previous Chiari osteotomy and that the osteotomy made the implantation of an acetabular component much easier. Migaud et al. ${ }^{20}$ reported that eleven (12\%) of ninety hips were converted to a total hip arthroplasty at an average of six years after a Chiari osteotomy and that all of the arthroplasties were easily performed without the need for acetabular bone-grafting. Hashemi-Nejad et al. ${ }^{21}$ reported perioperative complications after only one of twenty-eight total hip arthroplasties performed following a Chiari osteotomy and after five of fifty primary procedures (i.e., without a prior osteotomy) in a well-matched control group. There were no technical problems during and no complications after the three total hip arthroplasties that we performed following a Chiari osteotomy. 
The JOURnAl of BOnE \& JOINT SURGERY · JBJS.ORG VOLUME 86-A · NUMBER 7 · JULY 2004
Chiari Pelvic Osteotomy for Advanced Osteoarthritis in Patients With Hip Dysplasia
Although our sample is too small for us to draw a definite conclusion, these results suggest that a Chiari pelvic osteotomy might not increase the risk of complications with a subsequent total hip arthroplasty, particularly in comparison with the rate associated with a total hip arthroplasty performed after an intertrochanteric osteotomy.

The surgical approach is an important technical factor in the Chiari pelvic osteotomy. The approach should provide wide exposure to facilitate an osteotomy at the most appropriate level. When there is a high-riding greater trochanter, an appropriate osteotomy line can be obtained with use of a trochanteric osteotomy and a positive postoperative Trendelenburg sign can be avoided by transferring the greater trochanter distally'. Since 1990, we have preferred the Ollier lateral u approach, which provides a wider exposure of the entire lateral surface of the ilium than does the posterolateral approach.

The osteotomy level has also been described as one of the important factors influencing the outcome $e^{9,10,22-24}$. Chiari ${ }^{5}$ indicated that the empty space will be filled with strong fibrous tissue capable of transmitting load to the acetabular roof after osteotomy at a proximal level. He emphasized that the risks of the osteotomy are more pronounced when it is performed at too distal a level, since the proximal fragment can press excessively on the joint capsule. Matsuno et al. ${ }^{9}$ reported that seventy-four $(84 \%)$ of eighty-eight hips with an appropriate osteotomy level had a good clinical result at an average of 9.3 years postoperatively. Our good results in hips with an appropriate osteotomy level reinforce the importance of achieving the correct osteotomy level in this procedure.

The improvement in femoral head coverage by sufficient displacement of the fragment is technically important and also provides acetabular bone stock for subsequent total hip arthroplasty. The average improvement of $36^{\circ}$ in the center-edge angle in our series was similar to that achieved in previous studies ${ }^{6-8,10}$. We recommend trying to obtain ideal femoral head coverage with a postoperative center-edge angle of $30^{\circ}$ to $35^{\circ}$, which usually requires 1.5 to $2.5 \mathrm{~cm}$ of medial displacement of the distal fragment.

Trousdale et al. $^{25}$ reported that periacetabular osteotomies performed for treatment of Tönnis grade- 3 osteoarthri- tis produced inferior results, with eight of nine patients having a Harris hip score of $<70$ points at the time of the most recent follow-up. No hip in our series had complete obliteration of the joint space on preoperative radiographs, which may be one reason for our better results.

The Chiari pelvic osteotomy has mechanical advantages as it covers the femoral head with the osteotomized proximal fragment and medializes the hip center. Although our clinical results were inferior to those of total hip arthroplasty ${ }^{3,421}$, they were acceptable at the time of mid-term follow-up. We believe that the Chiari pelvic osteotomy is indicated for patients less than fifty years old with advanced Tönnis grade- 3 osteoarthritis associated with hip dysplasia who prefer a joint-conserving procedure to total hip arthroplasty and accept a clinical outcome that is predicted to be less optimal than that of total hip arthroplasty. Moderate dysplasia and moderate subluxation without complete obliteration of the joint space and a preoperative center-edge angle of at least $-10^{\circ}$ are desirable factors, and the osteotomy level should be appropriate. Preoperative education of the patient regarding the possibility of limited functional improvement is necessary.

NoTE: The authors thank William J. Maloney, MD, Washington University School of Medicine, for advice and critical comments on this study.

Hiroshi Ito, MD

Takeo Matsuno, MD

Department of Orthopaedic Surgery, Asahikawa Medical College, Higashi 2-1-1-1, Midorigaoka, Asahikawa 078-8510, Japan. E-mail address for H. Ito: itobiro@asahikawa-med.ac.jp

Akio Minami, MD

Department of Orthopaedic Surgery, Hokkaido University School of Medicine, Kita-ku Kita-15 Nishi-7, Sapporo 060-8638, Japan

The authors did not receive grants or outside funding in support of their research or preparation of this manuscript. They did not receive payments or other benefits or a commitment or agreement to provide such benefits from a commercial entity. No commercial entity paid or directed, or agreed to pay or direct, any benefits to any research fund, foundation, educational institution, or other charitable or nonprofit organization with which the authors are affiliated or associated.

\section{References}

1. Dorr LD, Luckett M, Conaty JP. Total hip arthroplasties in patients younger than 45 years. A nine- to ten-year follow-up study. Clin Orthop. 1990;260:215-9.

2. Sochart DH, Porter ML. The long-term results of Charnley low-friction arthroplasty in young patients who have congenital dislocation, degenerative osteoarthrosis, or rheumatoid arthritis. J Bone Joint Surg Am. 1997;79:1599-617.

3. Sullivan PM, MacKenzie JR, Callaghan JJ, Johnston RC. Total hip arthroplasty with cement in patients who are less than fifty years old. A sixteen to twenty-two-year follow-up study. J Bone Joint Surg Am. 1994;76:863-9.

4. Barrack RL, Mulroy RD Jr, Harris WH. Improved cementing techniques and femoral component loosening in young patients with hip arthroplasty. A 12-year radiographic review. J Bone Joint Surg Br. 1992;74:385-9.

5. Chiari K. Medial displacement osteotomy of the pelvis. Clin Orthop. 1974; 98:55-71.

6. Calvert PT, August AC, Albert JS, Kemp HB, Catterall A. The Chiari pelvic osteotomy. A review of the long-term results. J Bone Joint Surg Br. 1987; 69:551-5.
7. Høgh J, Macnicol MF. The Chiari pelvic osteotomy. A long-term review of clinical and radiographic results. J Bone Joint Surg Br. 1987;69:365-73.

8. Lack W, Windhager R, Kutschera HP, Engel A. Chiari pelvic osteotomy for osteoarthritis secondary to hip dysplasia. Indications and long-term results. J Bone Joint Surg Br. 1991;73:229-34.

9. Matsuno T, Ichioka Y, Kaneda K. Modified Chiari pelvic osteotomy: a longterm follow-up study. J Bone Joint Surg Am. 1992;74:470-8.

10. Ohashi H, Hirohashi K, Yamano Y. Factors influencing the outcome of Chiari pelvic osteotomy: a long-term follow-up. J Bone Joint Surg Br. 2000; 82:517-25.

11. Reynolds DA. Chiari innominate osteotomy in adults. Technique, indications and contra-indications. J Bone Joint Surg Br. 1986;68:45-54.

12. Windhager R, Pongracz N, Schonecker W, Kotz R. Chiari osteotomy for congenital dislocation and subluxation of the hip. Results after 20 to 34 years follow-up. J Bone Joint Surg Br. 1991;73:890-5.

13. Tönnis D. Congenital dysplasia and dislocation of the hip in children and 
The Journal of Bone \& JoInt Surgery • JBJS.org VOLUme 86-A · Number 7 · JuLY 2004
Chiari Pelvic Osteotomy for Advanced Osteoarthritis

in Patients With Hip Dysplasia adults. Telger TC, translator. New York: Springer; 1987. Translation of Angeborene Hüftdysplasie und Hüftluxation im Kindes und Erwachsenenalter.

14. Bost FC, Schottstaedt ER, Larsen LJ. Surgical approaches to the hip joint. Instr Course Lect. 1954;11:131-42.

15. Harris WH. Traumatic arthritis of the hip after dislocation and acetabular fractures: treatment by mold arthroplasty. An end-result study using a new method of result evaluation. J Bone Joint Surg Am. 1969;51:737-55.

16. Wiberg G. Studies on dysplastic acetabula and congenital subluxation of the hip joint. With special reference to the complication of osteoarthritis. Acta Chir Scand. 1939;83:58.

17. Sharp IK. Acetabular dysplasia. The acetabular angle. J Bone Joint Surg Br. 1961;43:268-72.

18. Heyman $\mathbf{C H}$, Herndon $\mathbf{C H}$. Legg-Perthes disease. A method for the measurement of the roentgenographic result. J Bone Joint Surg Am. 1950;32:767-78.

19. Ferguson GM, Cabanela ME, Ilstrup DM. Total hip arthroplasty after failed intertrochanteric osteotomy. J Bone Joint Surg Br. 1994;76:252-7.
20. Migaud H, Duquennoy A, Gougeon F, Fontaine C, Pasquier G. Outcome of Chiari pelvic osteotomy in adults. 90 hips with 2-15 years' follow-up. Acta Orthop Scand. 1995;66:127-31.

21. Hashemi-Nejad A, Haddad FS, Tong KM, Muirhead-Allwood SK, Catterall A. Does Chiari osteotomy compromise subsequent total hip arthroplasty? J Arthroplasty. 2002;17:731-9.

22. Fernandez DL, Isler B, Muller ME. Chiari's osteotomy. A note on technique. Clin Orthop. 1984;185:53-8.

23. Colton CL. Chiari osteotomy for acetabular dysplasia in young subjects. J Bone Joint Surg Br. 1972;54:578-89.

24. De Waal Malefijt MC, Hoogland T, Nielsen HK. Chiari osteotomy in the treatment of congenital dislocation and subluxation of the hip. J Bone Joint Surg Am. 1982;64:996-1004.

25. Trousdale RT, Ekkernkamp A, Ganz R, Wallrichs SL. Periacetabular and intertrochanteric osteotomy for the treatment of osteoarthrosis in dysplastic hips. J Bone Joint Surg Am. 1995;77:73-85. 